\title{
A comparison of two assessment tools used in overviews of systematic reviews: ROBIS versus AMSTAR-2
}

\author{
R. Perry ${ }^{1 *} \mathbb{D}$, A. Whitmarsh ${ }^{1}$, V. Leach² and P. Davies ${ }^{2,3}$
}

\begin{abstract}
Background: AMSTAR-2 is a 16-item assessment tool to check the quality of a systematic review and establish whether the most important elements are reported. ROBIS is another assessment tool which was designed to evaluate the level of bias present within a systematic review. Our objective was to compare, contrast and establish both inter-rater reliability and usability of both tools as part of two overviews of systematic reviews. Strictly speaking, one tool assesses methodological quality (AMSTAR-2) and the other assesses risk of bias (ROBIS), but there is considerable overlap between the tools in terms of the signalling questions.

Methods: Three reviewers independently assessed 31 systematic reviews using both tools. The inter-rater reliability of all sub-sections using each instrument (AMSTAR-2 and ROBIS) was calculated using Gwet's agreement coefficient ( $A C_{1}$ for unweighted analysis and $A C_{2}$ for weighted analysis).

Results: Thirty-one systematic reviews were included. For AMSTAR-2, the median agreement for all questions was 0.61. Eight of the 16 AMSTAR-2 questions had substantial agreement or higher $(>0.61)$. For ROBIS, the median agreement for all questions was also 0.61. Eleven of the 24 ROBIS questions had substantial agreement or higher.

Conclusion: ROBIS is an effective tool for assessing risk of bias in systematic reviews and AMSTAR-2 is an effective tool at assessing quality. The median agreement between raters for both tools was identical (0.61). Reviews that included a meta-analysis were easier to rate with ROBIS; however, further developmental work could improve its use in reviews without a formal synthesis. AMSTAR-2 was more straightforward to use; however, more response options would be beneficial.
\end{abstract}

Keywords: AMSTAR-2, ROBIS, Systematic reviews, Methodological quality, Risk of bias

\section{Background}

Systematic reviews have become a fundamental part of evidence-based medicine; they are considered the highest form of evidence as they synthesise all available evidence on a given topic [1]. Many will also combine data to give an overall effect estimate using a meta-analysis.

\footnotetext{
*Correspondence: Rachel.Perry@bristol.ac.uk

${ }^{1}$ National Institute for Health Research Bristol Biomedical Research

Centre, University Hospitals Bristol and Weston NHS Foundation Trust and University of Bristol, Bristol, UK

Full list of author information is available at the end of the article
}

However, the quality and standard of reviews varies considerably. If this is not understood, or in some way established, the results of many reviews might be overstated. Quality assessment tools have been developed to assess such variation in standards.

One previously heavily cited tool is the Assessment of Multiple Systematic Reviews (AMSTAR) scale [2] which has been widely used since its development in 2007. This scale was shown to be both reliable and valid [3]. However, it came under criticism for some issues with its design. It was argued by Burda et al. [4] that AMSTAR was lacking in some key constructs, in particular, the original author(s) and the source, provide a link to the Creative Commons licence, and indicate if changes were made. The images or other third party material in this article are included in the article's Creative Commons licence, unless indicated otherwise in a credit line to the material. If material is not included in the article's Creative Commons licence and your intended use is not permitted by statutory regulation or exceeds the permitted use, you will need to obtain permission directly from the copyright holder. To view a copy of this licence, visit http://creativecommons.org/licenses/by/4.0/. The Creative Commons Public Domain Dedication waiver (http://creativeco mmons.org/publicdomain/zero/1.0/) applies to the data made available in this article, unless otherwise stated in a credit line to the data. 
confidence in the estimates of effect. It also lacks an item to assess subgroup and sensitivity analysis. Further criticisms include issues such as the inclusion of foreign language papers as "grey literature" and the idea that the items can often partially but not fully meet the criteria was highlighted. Also, each item was not weighted evenly and there is a lack of overall score, which became problematic when trying to compare scores. Thus, an upgraded version (AMSTAR-2) was developed in 2017. The new version promised to simplify the response categories, align the definition of research questions with the PICO (population, intervention, control group, outcome) framework, seek justification for the review authors' selection of different study designs (randomised and nonrandomised) and included numerical rating scales for inclusion in systematic reviews, seek reasons for exclusion of studies from the review, and determine whether the review authors had made a sufficiently detailed assessment of risk of bias for the included studies and whether risk of bias was considered adequately during statistical pooling and when interpreting the results [5].

A second novel assessment tool that has undergone rigorous development was published in 2016 (Risk of Bias in Systematic reviews [ROBIS [6]]). It aimed to provide a thorough and robust assessment of the level of bias within the systematic review.

\section{Description of the assessment tools Assessment of multiple systematic reviews (AMSTAR-2)}

The main aim of the AMSTAR-2 is a tool to assess the methodological quality of the review. It is made up of 16 items in total and has simpler response categories than the original AMSTAR version. Some sections are considered by the authors to be critical domains, which can be used for determining an overall score (see Appendix, Table 12 for more information on the critical domains). AMSTAR-2 is intended for assessing effectiveness. The tool can also be applied to reviews of both randomised and non-randomised studies.

\section{ROBIS tool}

The main aim of the ROBIS tool is to evaluate the level of bias present within a systematic review. The tool is made up of three distinct phases. Firstly, there is an optional first phase to assess the applicability of the review to the research question of interest. The second phase is made up of 20-items within four main domains: study eligibility criteria, identification and selection of studies, data collection and study appraisal, synthesis and findings. This phase is to identify concerns about the review conduct. Each domain has signalling questions and ends with a judgement of concerns of each domain (low, high or unclear). There is also a third phase consisting of three signalling questions to enable an overall assessment of bias rating to be given. ROBIS has a wide application and is intended for assessing effectiveness, diagnostic test accuracy, prognosis and aetiology [6].

\section{Previous research}

Due to the novelty of both tools, there is limited available literature comparing them; however, some work has been recently published.

One review team $[7,8]$ compared all three tools (AMSTAR, AMSTAR-2 and ROBIS), applying them to reviews that reported both randomised and non-randomised trials. The inter-rater reliability between four raters' across 30 systematic reviews was analysed. Minor differences were found between AMSTAR-2 and ROBIS in the assessment of systematic reviews including a mix of study type. On average, the inter-rater reliability (IRR) was higher for AMSTAR-2 compared to ROBIS. They assumed that scoring ROBIS would take more time in general, and it was always applied after AMSTAR-2, but in fact the mean time for scoring AMSTAR-2 was slightly higher than for ROBIS (18 vs. $16 \mathrm{~min}$ ), with huge variation between the reviewers. They also reported that some signalling questions in ROBIS were judged to be very difficult to assess.

\section{Aim}

The overarching aim of our work is to add to the literature and make a further comparison of both assessment tools in two overviews of reviews. Our team had previously completed two overviews on complementary and alternative medicine (CAM) therapies for two hard-totreat conditions. One overview evaluated systematic reviews of various CAM therapies for fibromyalgia (FM) [9], and the other evaluated systematic reviews of CAM therapies for infantile colic [10].

\section{Objectives}

Due to some of the challenges we had using both tools in our overview of reviews work, we planned a formal assessment of both tools by completing the following comparisons and evaluations:

1. To compare the content of the tools

2. To compare the percentage agreement (IRR)

3. To assess the useability/user experience of both tools.

\section{Methods}

Two overviews of reviews were conducted by our team $[9,10]$. The first reviewed CAM for fibromyalgia and assessed the included reviews using both the original AMSTAR tool [2] and ROBIS [6]. This review was 
published in 2016, prior to the development and publication of AMSTAR-2 [5]. Here, we reported on 15 systematic reviews of CAM for fibromyalgia, published between 2003 and 2014 which assessed several CAM therapies. Eight of the reviews included a quantitative synthesis.

We subsequently completed a second overview of reviews of CAM for infantile colic published in 2019 [10]. Here, we used the new AMSTAR-2 tool alongside ROBIS. We reported on 16 systematic reviews of CAM for colic, published between 2011 and 2018 . The reviews investigated several CAM therapies, 12 of which included a quantitative synthesis.

We later returned to the fibromyalgia review papers and reassessed them all using the AMSTAR-2 scale, for consistency. This results in a total comparison of 31 reviews. The reviewers were not strict about the order of ratings.

\section{Assessment of methodological quality/bias of the included reviews}

Three reviewers (RP, VL, PD) independently assessed each systematic review using both tools. Any reported meta-analyses were checked by a statistician experienced in meta-analyses (CP). The final score was agreed after discussion between the authors.

\section{Data-analysis}

Gwet's AC statistic was used to calculate inter-rater reliability (IRR) [11]. Gwet's AC2 is a weighted statistic which allows for "partial agreement" between ordinal categories. Therefore, Gwet's AC2 was used to calculate IRR (using linear weights) for AMSTAR-2 questions with options "no", "partial yes" and "yes" (questions 2, $4,7,8,9)$. Gwet's AC1 is an unweighted statistic which measures full agreement only. Gwet's AC1 was used for all other AMSTAR-2 questions.

All signalling questions for ROBIS were analysed using Gwet's AC2 with linear weights where "no", "probably no", "probably yes" and "yes" were recoded as 1-4. As mentioned above, Gwet's AC2 is a weighted statistic which allows for "partial agreement" between ordinal categories. Ratings of "no information" were treated as missing. Gwet's AC1 was used for ROBIS domains. Agreement for AMSTAR-2 and ROBIS was classified as "poor" $(\leq 0.00)$, "slight" (0.01-0.20), "fair" (0.21-0.40), "moderate" (0.41-0.60), "substantial" (0.61-0.80), and "almost perfect" (0.81-1.00), following accepted criteria [12]. All analyses were completed using Stata 16 (StataCorp. 2019; Stata Statistical Software).

\section{Results}

Our first objective was to compare the content of the tools (see Table 1). Any overlaps and discrepancies between the two scales are identified. Overall, we found considerable overlap on the signalling questions. However, ROBIS does not assess whether there is a comprehensive list of studies (both included and excluded) or whether any conflicts of interest were declared (both at the individual trial level and for the reviews), as these are considered issues of methodology quality rather than bias. AMSTAR-2 also assessed possible conflicts of interest, which is not assessed in ROBIS, despite being a potential risk of bias. However, the section on synthesis was given more in-depth consideration in ROBIS tool.

\section{Section 2: Comparison of the inter-rater reliability of the tools AMSTAR-2}

The consensus results for AMSTAR-2 of both fibromyalgia and colic overviews can be found in Table 2. We report on 15 systematic reviews of CAM for fibromyalgia and found all but one review [13] rated as having critically low confidence in the results (see Appendix, Table 15 for scoring information). This was the only Cochrane review included in the FM overview. We also report on 16 systematic reviews of CAM for colic. Most were rated as having critically low confidence in the results, 4 were rated as low and 1 (a Cochrane review) was considered to have high confidence in the results. The comparison of the ratings for each review can be found in the Appendix (see Tables 9, 10, 13, and 14). There were a greater number of discrepancies between the overall risk of bias and quality ratings in the fibromyalgia reviews. The overall risk of bias/quality ratings was more consistent in the colic reviews.

Results of inter-rater reliability analysis for AMSTAR-2 A summary of the inter-rater reliability [IRR] for AMSTAR-2 can be found in Table 3. Seven questions that relate to critical domains were identified by Shea et al. [5]; more information about these domains can be found in Appendix (Table 15).

Summary of the findings on Inter-rater reliability In total, 460 comparisons were included in the analysis for AMSTAR-2. The median agreement for all questions was 0.61 . Eight of the 16 AMSTAR-2 questions had substantial agreement or higher. There was almost perfect agreement for questions 2 (did the report of the review contain an explicit statement that the review methods were established prior to the conduct of the review and 


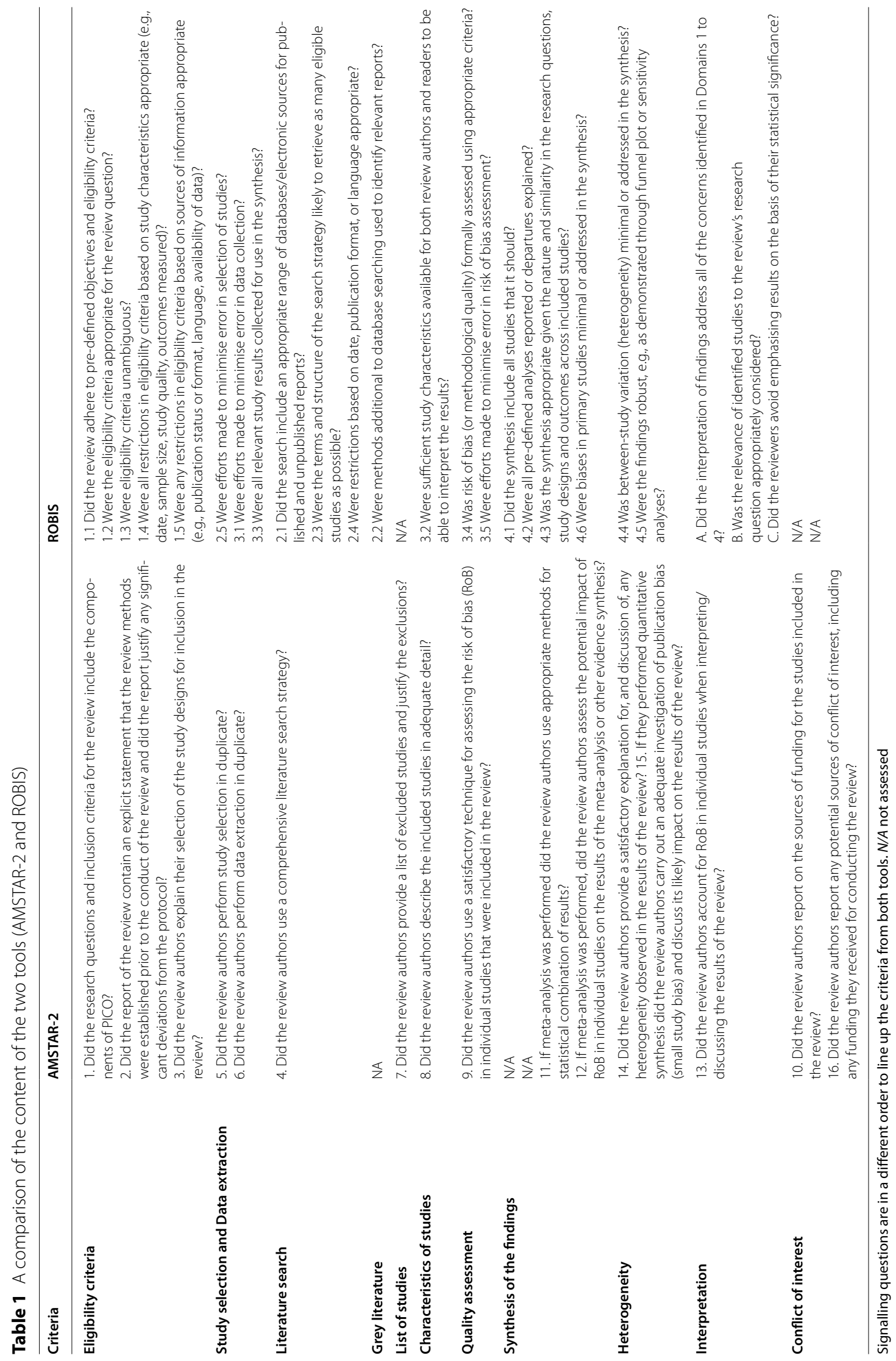




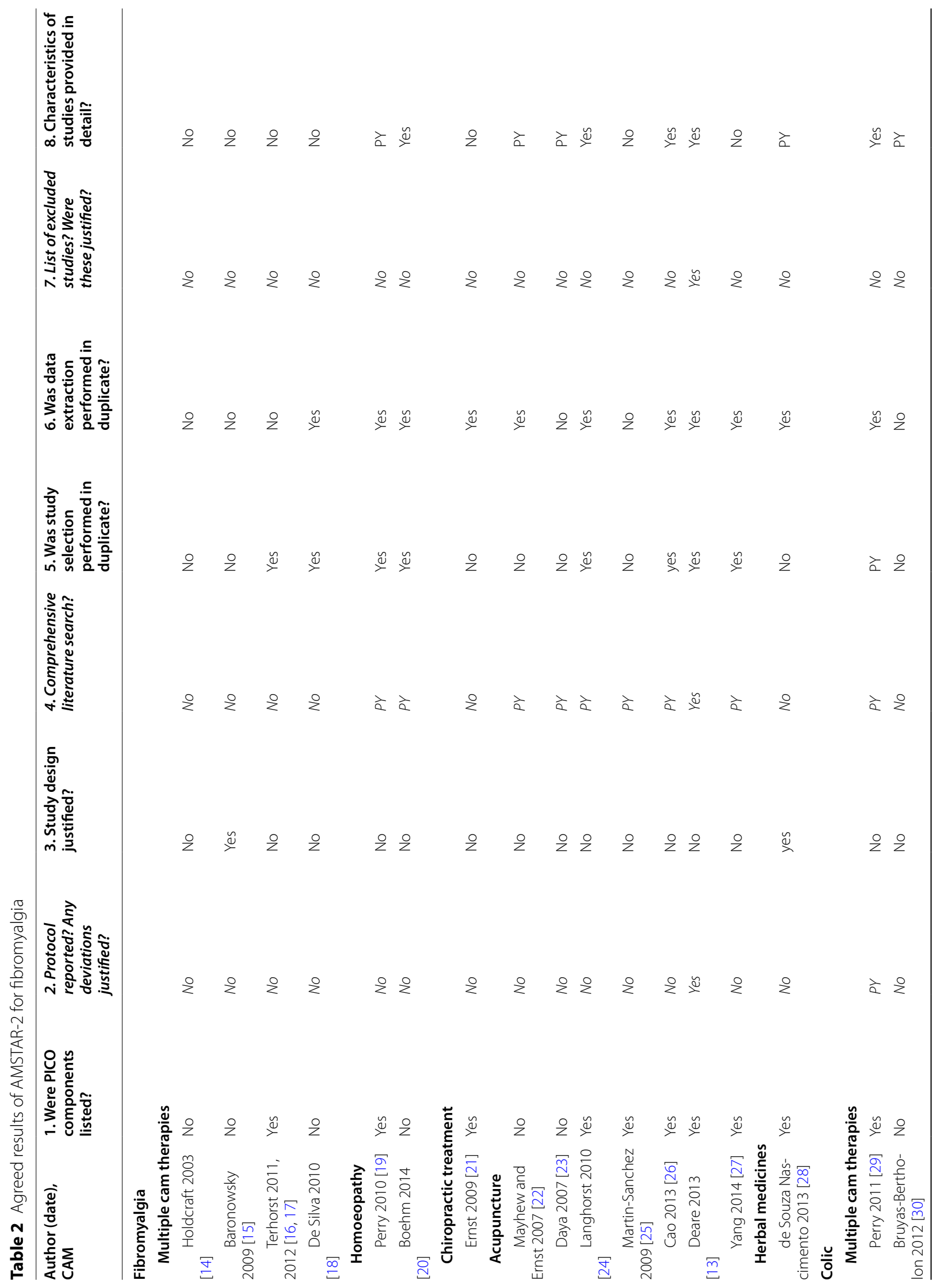




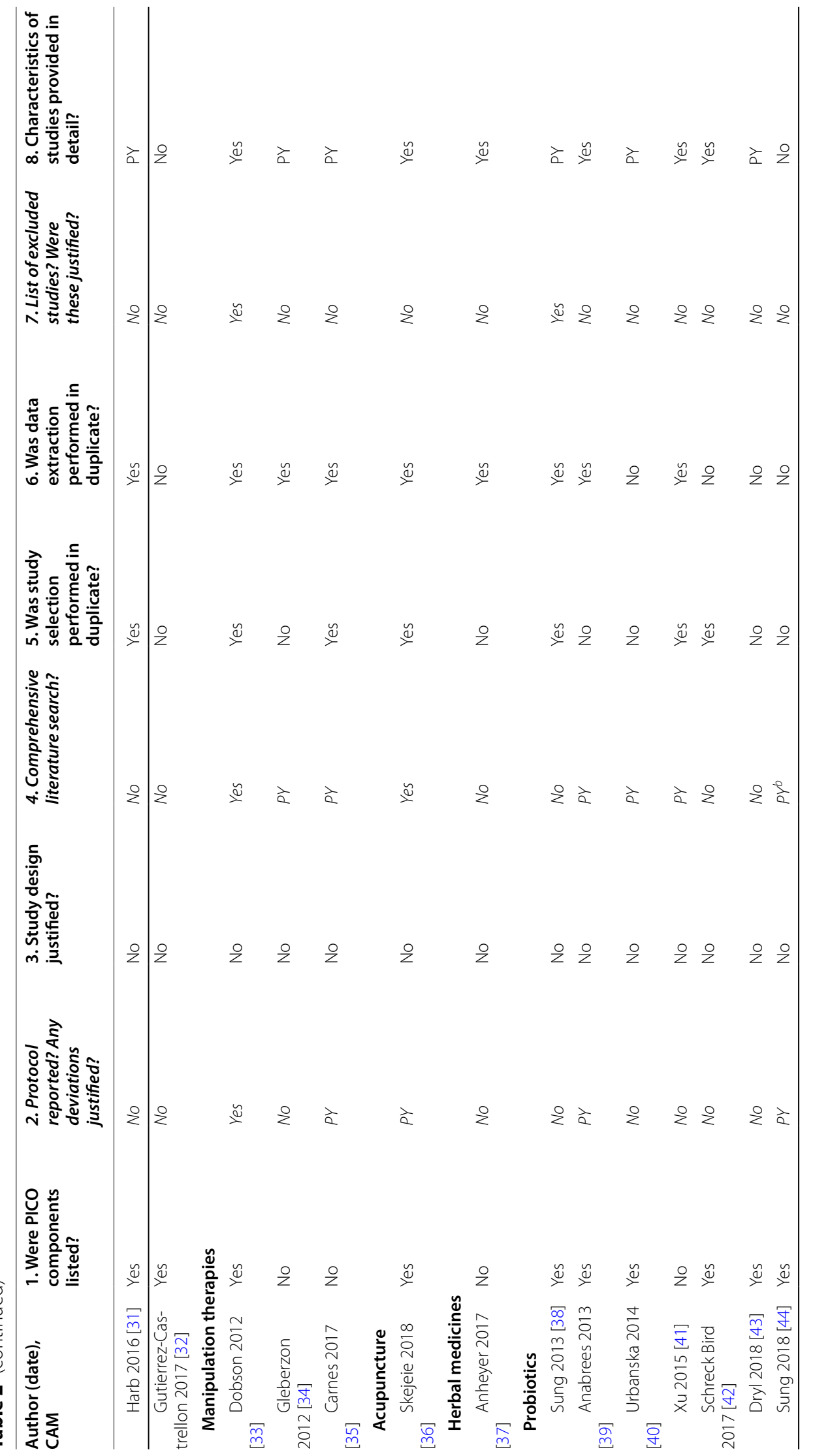




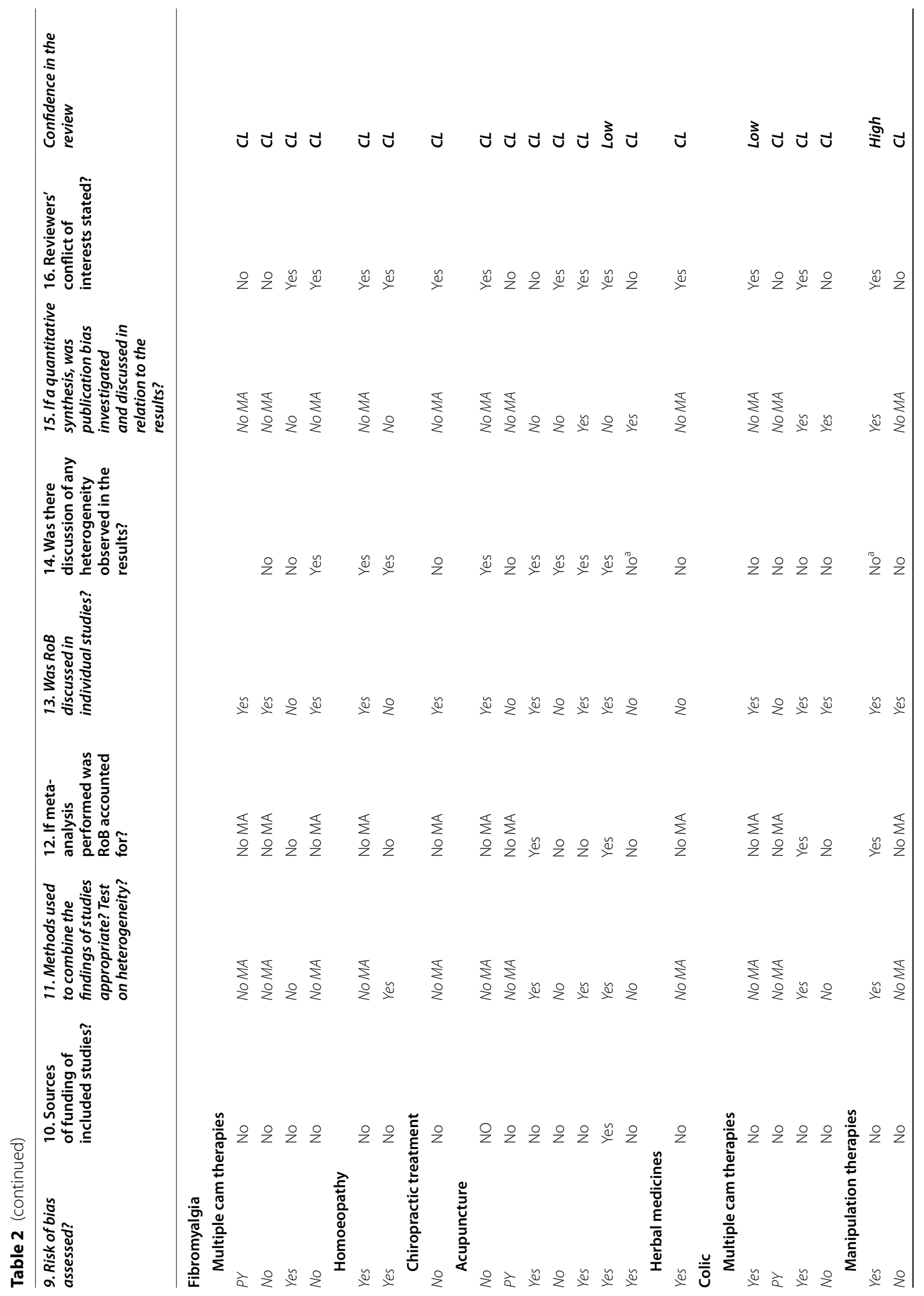




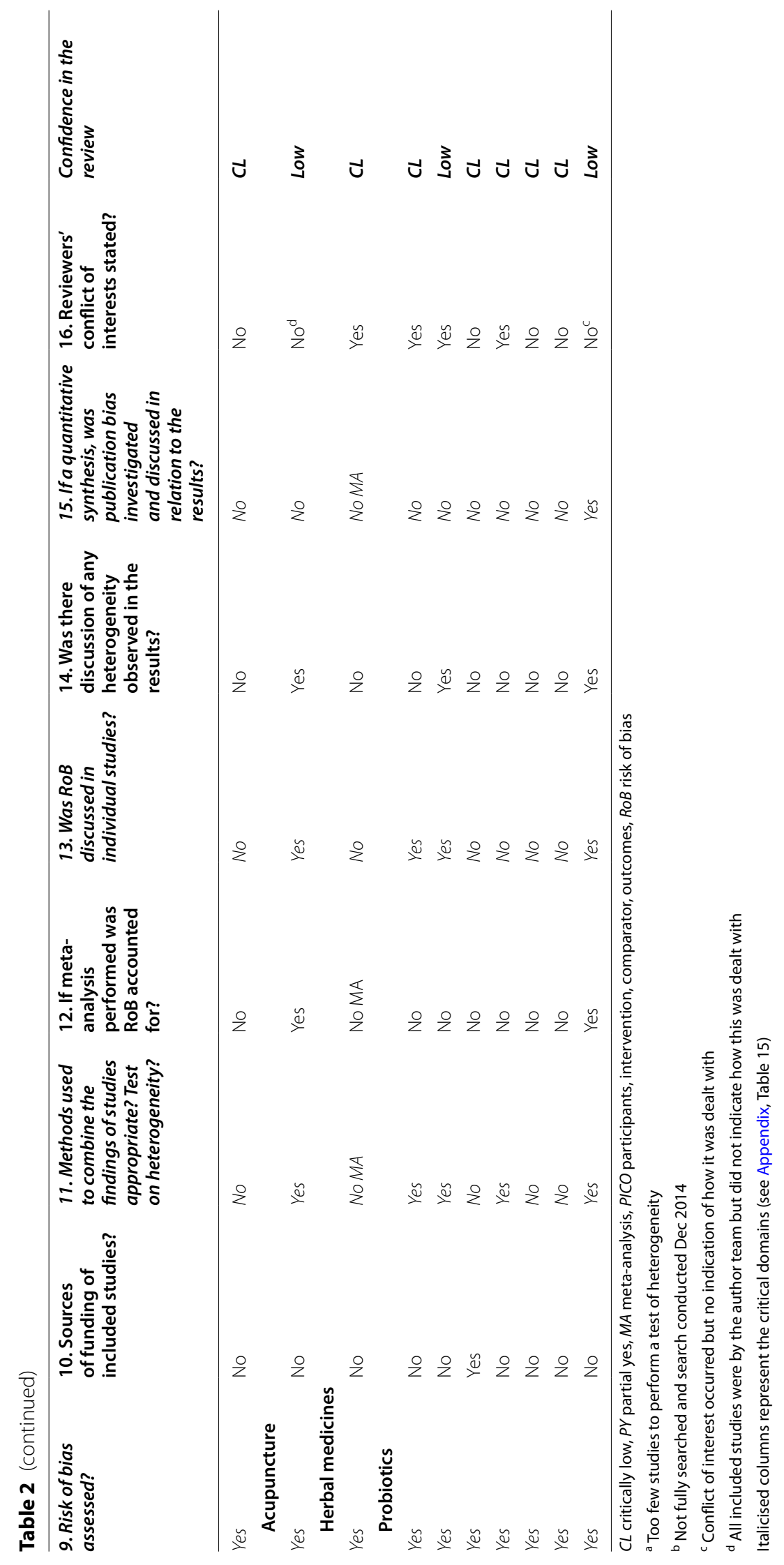


Table 3 The inter-rater agreement between the three raters for AMSTAR-2

\begin{tabular}{llll}
\hline Question & $\begin{array}{l}\text { Number of } \\
\text { studies }\end{array}$ & $\begin{array}{l}\text { Gwet's AC1/Gwet's } \\
\text { AC2 }\end{array}$ & $\mathbf{9 5 \% ~ C l}$ \\
\hline 1 & 31 & 0.69 & $0.48,0.91$ \\
2 & 31 & 0.93 & $0.85,1.00$ \\
3 & 31 & 0.55 & $0.30,0.80$ \\
4 & 31 & 0.66 & $0.51,0.81$ \\
5 & 31 & 0.70 & $0.47,0.94$ \\
6 & 31 & 0.60 & $0.35,0.86$ \\
7 & 31 & 0.97 & $0.94,1.00$ \\
8 & 31 & 0.39 & $0.21,0.56$ \\
9 & 31 & 0.65 & $0.46,0.84$ \\
10 & 31 & 0.84 & $0.67,1.00$ \\
11 & 19 & 0.54 & $0.19,0.89$ \\
12 & 19 & 0.40 & $0.05,0.75$ \\
13 & 31 & 0.52 & $0.27,0.78$ \\
14 & 31 & 0.19 & $-0.08,0.47$ \\
15 & 19 & 0.61 & $0.28,0.94$ \\
16 & 31 & 0.34 & $0.06,0.63$ \\
\hline
\end{tabular}

did the report justify any significant deviations from the protocol?), 7 (did the review authors provide a list of excluded studies and justify the exclusions?) and 10 (did the review authors report on the sources of funding for the studies included in the review?). The lowest agreement was for question 14 (did the review authors provide a satisfactory explanation for, and discussion of, any heterogeneity observed in the results of the review?). Ratings were missing in 35 cases. The results are displayed in Fig. 1.

The AMSTAR-2 critical questions, in particular, seemed to have good agreement compared to the other questions. There was at least substantial agreement for all critical questions except question 13 which had moderate agreement. Questions 2 and 7 both had almost perfect agreement and had the highest agreement of all AMSTAR-2 questions.

Gwet's AC2 statistic was used for questions 2, 4, 7, 8 and 9. Gwet's AC1 statistic was used for all other questions. The markers represent the Gwet's statistic and the error bars represent the 95\% confidence intervals. The italicised data represent the median value for all questions.

Further information on the separate reviews can be found in the Appendix (Tables 7 and 11). The overall median IRR agreement for AMSTAR-2 questions for fibromyalgia is 0.65 and for colic is 0.60 .

\section{ROBIS}

Summary of the ROBIS results The consensus results for ROBIS for both fibromyalgia and colic overviews can be found in Table 4. With regard to the ROBIS results, domain 1 (which assessed any concerns regarding specification of study eligibility criteria), 9 fibromyalgia

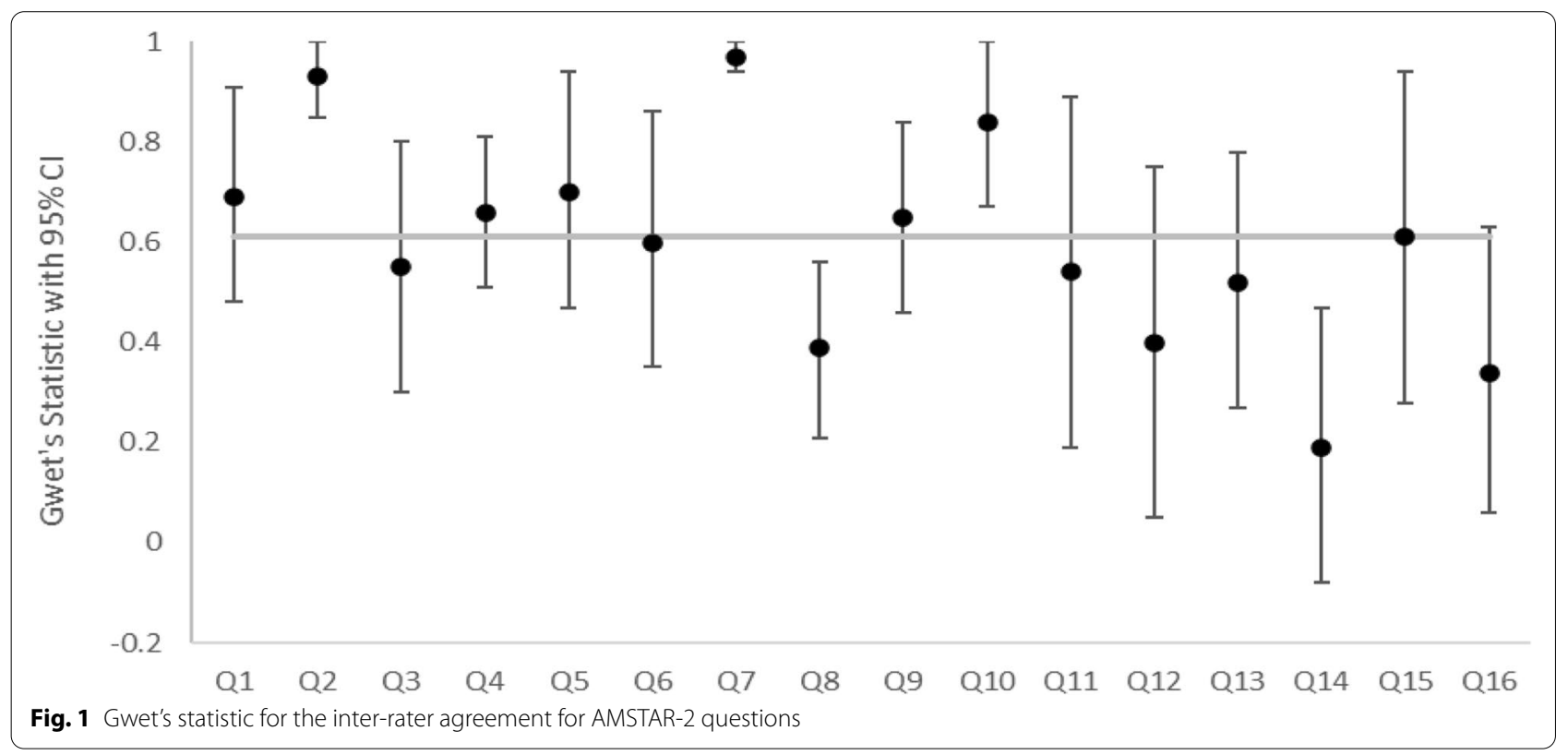


Table 4 Tabular presentation for agreement of ROBIS results

\begin{tabular}{|c|c|c|c|c|c|}
\hline \multirow[t]{2}{*}{ Fibromyalgia review } & \multicolumn{4}{|l|}{ Phase 2} & \multirow{2}{*}{$\begin{array}{l}\text { Phase } 3 \\
5 . \text { Risk of bias in the review }\end{array}$} \\
\hline & 1. Study eligibility criteria & $\begin{array}{l}\text { 2. Identifica- } \\
\text { tion and } \\
\text { selection of } \\
\text { studies }\end{array}$ & $\begin{array}{l}\text { 3. Data } \\
\text { collection } \\
\text { and study } \\
\text { appraisal }\end{array}$ & 4. Synthesis and findings & \\
\hline \multicolumn{6}{|l|}{ Homoeopathy } \\
\hline 1. Perry & Low & Low & Low & Unclear & Low \\
\hline 2. Boehm & High & Low & Low & High & High \\
\hline \multicolumn{6}{|l|}{ Acupuncture } \\
\hline 3. Mayhew & Low & High & High & Low & Low \\
\hline 4. Daya & Low & High & High & Low & Low \\
\hline 5. Langhorst & Low & High & High & Low & Low \\
\hline 6. Martin-Sanchez & Low & High & High & High & High \\
\hline 7. Cao & Low & High & Low & Low & Low \\
\hline 8. Deare & Low & Low & Low & Low & Low \\
\hline 9. Yang & Low & Low & High & High & High \\
\hline \multicolumn{6}{|l|}{ Chiropractic } \\
\hline 10. Ernst & High & Unclear & High & Unclear & Unclear \\
\hline \multicolumn{6}{|l|}{ Herbal Medicine } \\
\hline 11. Nascimento & Low & Low & Low & High & Low \\
\hline \multicolumn{6}{|l|}{ Multiple CAM reviews } \\
\hline 12. Holdcraft & Low & Low & Low & High & Low \\
\hline 13. Baronowsky & Low & Low & Unclear & High & Low \\
\hline 14. Terhorst & Low & High & Low & High & High \\
\hline 15. De Silva & High & High & High & Unclear & Low \\
\hline \multirow[t]{2}{*}{ Colic review } & Phase 2 & & & & Phase 3 \\
\hline & 1. Study eligibility criteria & $\begin{array}{l}\text { 2. Identifica- } \\
\text { tion and } \\
\text { selection of } \\
\text { studies }\end{array}$ & $\begin{array}{l}\text { 3. Data } \\
\text { collection } \\
\text { and study } \\
\text { appraisal }\end{array}$ & 4. Synthesis and findings & 5. Risk of bias in the review \\
\hline \multicolumn{6}{|l|}{ Multiple CAM therapies } \\
\hline 1. Perry & Low & Unclear & Low & Low & Low \\
\hline 2. Bruyas-Bertholon & High & High & Unclear & High & High \\
\hline 3. Harb & High & High & Low & High & High \\
\hline 4. Gutierrez-Castrellon & Unclear & High & High & High & High \\
\hline \multicolumn{6}{|c|}{ Manipulation therapies } \\
\hline 5. Dobson & Low & Low & Low & Low & Low \\
\hline 6. Gleberzon & High & High & Unclear & Unclear & High \\
\hline 7. Carne & Low & Low & Low & High & Unclear \\
\hline \multicolumn{6}{|l|}{ Acupuncture } \\
\hline 8. Skejeie & Low & Low & Low & Low & Unclear \\
\hline \multicolumn{6}{|l|}{ Herbal medicine } \\
\hline 9. Anheyer & Unclear & High & Low & High & High \\
\hline \multicolumn{6}{|l|}{ Probiotics } \\
\hline 10. Sung 2013 & Unclear & Low & Low & High & Unclear \\
\hline 11. Anabrees & Low & Low & Low & High & Low \\
\hline 12. Urbansk & Low & High & High & High & High \\
\hline 13. Xu & Unclear & Low & Low & Unclear & Low \\
\hline 14. Shreck Bird & High & High & Low & High & High \\
\hline 15. Dryl & High & High & Unclear & High & High \\
\hline 16. Sung 2018 & High & Unclear & Unclear & Unclear & Unclear \\
\hline
\end{tabular}


reviews achieved a low risk of bias rating overall and 6 colic reviews achieved a low risk of bias rating overall. In domain 2 (which assessed concerns regarding methods used to identify and/or select studies), 7 fibromyalgia reviews achieved a low risk of bias rating overall and 6 colic reviews achieved a low risk of bias rating overall.

Domain 3 assessed concerns regarding methods used to collect data and appraise studies; 7 fibromyalgia studies and 10 colic reviews achieved a low risk of bias rating overall.

With regard to domain 4 (which assessed concerns regarding the synthesis and findings), more variation in the fibromyalgia scores was found, whereas most colic reviews were rated as high risk of bias in this domain. The reviews that did not conduct a meta-analysis were hard to assess using ROBIS.

The final section provides a rating for the overall risk of bias of the reviews; 7 fibromyalgia reviews achieved a low rating; 6 , a high rating; and 2, were rated as unclear. Four colic reviews achieved a low rating; 4 , an unclear rating; and 8 , a high rating.

Results of inter-rater reliability analysis for ROBIS A summary of the inter-rater reliability for ROBIS can be found in Table 5.

Table 5 Inter-rater agreement

\begin{tabular}{|c|c|c|c|}
\hline ROBIS question & No. of studies & $\begin{array}{l}\text { Gwet's AC1/ } \\
\text { Gwet's AC2 }\end{array}$ & $95 \% \mathrm{Cl}$ \\
\hline \multicolumn{4}{|l|}{ Domain 1: study eligibility criteria } \\
\hline 1.1 & 30 & 0.62 & $0.38,0.85$ \\
\hline 1.2 & 31 & 0.70 & $0.56,0.84$ \\
\hline 1.3 & 31 & 0.69 & $0.56,0.82$ \\
\hline 1.4 & 31 & 0.61 & $0.48,0.74$ \\
\hline 1.5 & 31 & 0.56 & $0.37,0.74$ \\
\hline Domain 1 Concerns regarding specification of study eligibility criteria & 31 & 0.45 & $0.22,0.67$ \\
\hline \multicolumn{4}{|l|}{ Domain 2: identification and selection of studies } \\
\hline 2.1 & 31 & 0.53 & $0.41,0.65$ \\
\hline 2.2 & 30 & 0.53 & $0.35,0.71$ \\
\hline 2.3 & 31 & 0.62 & $0.47,0.77$ \\
\hline 2.4 & 31 & 0.41 & $0.20,0.62$ \\
\hline 2.5 & 29 & 0.59 & $0.30,0.88$ \\
\hline Domain 2 Concerns regarding methods used to identify and/or select studies & 31 & 0.36 & $0.17,0.55$ \\
\hline \multicolumn{4}{|l|}{ Domain 3: data collection and study appraisal } \\
\hline 3.1 & 29 & 0.88 & $0.68,1.00$ \\
\hline 3.2 & 31 & 0.66 & $0.51,0.82$ \\
\hline 3.3 & 31 & 0.65 & $0.51,0.78$ \\
\hline 3.4 & 31 & 0.77 & $0.61,0.93$ \\
\hline 3.5 & 30 & 0.73 & $0.48,0.98$ \\
\hline Domain 3 Concerns regarding methods used to collect data and appraise studies & 31 & 0.55 & $0.35,0.76$ \\
\hline \multicolumn{4}{|l|}{ Domain 4: synthesis and findings } \\
\hline 4.1 & 31 & 0.60 & $0.46,0.74$ \\
\hline 4.2 & 29 & 0.48 & $0.28,0.68$ \\
\hline 4.3 & 31 & 0.77 & $0.66,0.88$ \\
\hline 4.4 & 31 & 0.18 & $-0.02,0.37$ \\
\hline 4.5 & 30 & 0.22 & $0.02,0.43$ \\
\hline 4.6 & 31 & 0.39 & $0.17,0.62$ \\
\hline Domain $\mathbf{4}$ Concerns regarding the synthesis and findings & 31 & 0.17 & $-0.03,0.37$ \\
\hline \multicolumn{4}{|l|}{ Risk of bias in the review } \\
\hline A & 31 & 0.28 & $0.09,0.47$ \\
\hline B & 31 & 0.64 & $0.54,0.75$ \\
\hline C & 31 & 0.45 & $0.31,0.60$ \\
\hline ROB & 31 & 0.45 & $0.24,0.66$ \\
\hline
\end{tabular}


Summary of the findings on Inter-rater reliability For ROBIS, there were 734 comparisons considered for the 24 questions. The median agreement for all questions was 0.61. Eleven of the 24 ROBIS questions had substantial agreement or higher. Ratings were missing in 9 cases. At least one rater said "no information" in 159 comparisons. Rater 1 used "no information" 73 times; rater 2, 50 times; and rater 3, 93 times. In 107 comparisons only one rater said "no information" and the raters all agreed only in 10 comparisons. "No information" was used most frequently for question 1.1 (did the review adhere to predefined objectives and eligibility criteria? 23 studies), question 4.2 (were all pre-defined analyses reported or departures explained? 22 studies) and question 4.5 (were the findings robust, e.g., as demonstrated through funnel plot or sensitivity analyses? 16 studies). The agreement was "moderate" for domains $1(0.45)$ and $3(0.36)$ and for the overall risk of bias (0.45). The agreement for domains 2 and 4 were "fair" (0.36) and "slight" (0.17), respectively. The results are summarised in Fig. 2.

Gwet's AC2 statistic was used for the ROBIS questions (filled markers) and Gwet's AC1 statistic was used for the ROBIS domains (hollow markers). The error bars represent the $95 \%$ confidence intervals. The italicised data represent the median value for all ROBIS questions.

Further information on the separate reviews can be found in the appendix (Tables 8 and 12). The median IRR agreement for all ROBIS questions for FM is 0.55 and for colic is 0.63 .

\section{Section 3: Usability of the tools}

All three raters felt AMSTAR-2 was more straightforward and user-friendly than ROBIS. This might be because it does not require expertise in systematic reviewing to complete this tool, just knowledge of trial design.

Several issues arose from using the ROBIS tool as it required more consideration to complete. Within each domain, each question had five possible responses (yes, probably yes, probably no, no, no information), although at times it was difficult to distinguish between yes/probably yes and no/probably no. It also might be more helpful to have a choice of "no concerns/minor concerns/ major concerns/considerable concerns", instead of "low/high/ unclear" judgements that are currently at the end of each domain when assessing the overall judgement of concerns. Although there were perceived differences in the individual answers to each signalling question between reviewers, the overall rating of the domains was more consistent. Overall, domains 1-3 were easier to follow and score.

The most difficult domain to score was domain 4 which covers "synthesis of evidence". This was reflected in the lowest agreement between raters (0.17). We found that this domain is currently better designed for a review with a meta-analysis, rather than a narrative synthesis. The

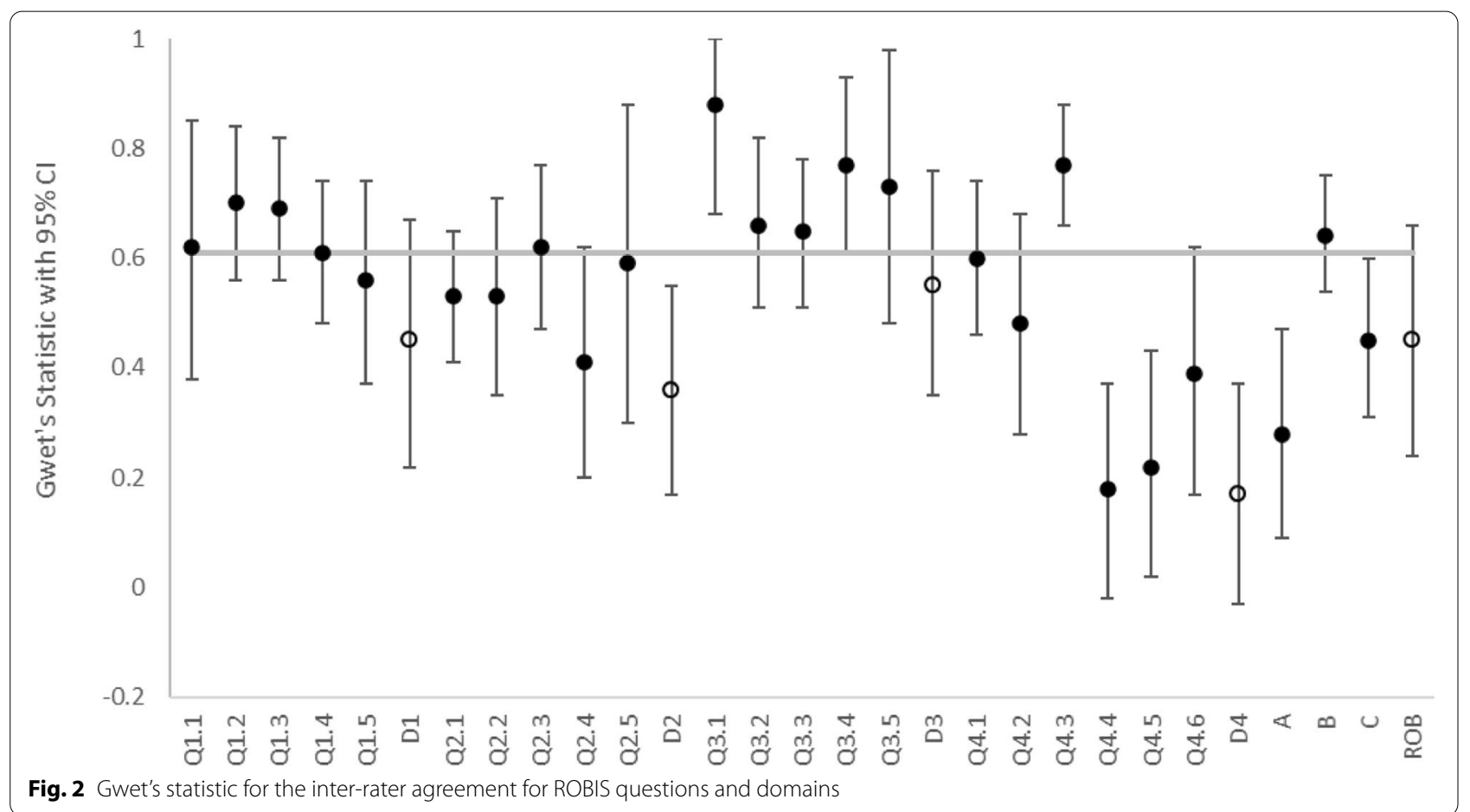


Table 6 Mean (SD) completion time (in minutes) for colic paper

\begin{tabular}{|c|c|c|c|c|c|c|}
\hline & \multicolumn{2}{|c|}{ Rater 1} & \multicolumn{2}{|c|}{ Rater 2} & \multicolumn{2}{|c|}{ Rater 3} \\
\hline & $n$ & Mean (SD) & $n$ & Mean (SD) & $n$ & Mean (SD) \\
\hline AMSTAR-2 & 14 & $13.0(5.2)$ & 15 & $18.7(6.6)$ & 16 & $11.1(4.2)$ \\
\hline ROBIS & 9 & $14.1(6.5)$ & 10 & $15.7(5.3)$ & 15 & $43.3(23.3)$ \\
\hline
\end{tabular}

guidance document that accompanies the tool is long and difficult to navigate. On the plus side, despite having subjective opinions (within each domain there was variation between the reviewers' responses to the signalling questions), you can still end with a moderately consistent overall result (0.45).

The ROBIS tool provides an overall sense of risk of bias of the review. There is better coverage overall than AMSTAR-2 and more precision with the use of a final rating. From our observations only, higher quality reviews were quicker to appraise. In our analysis, the "no information" rating for ROBIS questions was treated as missing. The raters rarely agreed on when to use this rating. In most cases, when one rater reported "no information" for a ROBIS question, the other two raters gave a different rating.

Several issues arose from using AMSTAR-2. Sometimes, the raters would have opted for a "partially yes" option when only a binary option (yes/no) was available (Q13, Q14, Q16). Also, some questions were ambiguous; in particular, Q3 asks if authors explain their selection of study design (e.g., use of RCTs/non RCTs); some reviews merely report they included RCTs rather than justifying their selection, which caused discrepancies between raters.

Also, some questions might elicit a different response depending on the outcome, e.g., Q13 (whether risk of bias was discussed/interpreted within the results), which may vary depending on whether there were multiple outcomes, and thus, which outcome is being referred to.

The raters also felt it would be helpful to have a formal space to add comments to justify their decision to help with discussions, as in the more ambiguous reviews; decisions were more open to interpretation. ROBIS, on the other hand, has a large section where the reviewer is expected to add selected text to support their decision.

Regarding completion timings, we were able to establish how long it took to complete both tools for one of the overviews (colic). There was little difference in timings between rater 1 and 2 to complete both tools; in fact, it took rater 2 slightly longer to complete AMSTAR-2 than ROBIS which is surprising, considering the issues reported above. However, rater 3 took considerably longer to complete ROBIS than AMSTAR-2 (see Table 6).
Rater 3 was the most experienced reviewer and helped develop the ROBIS tool. They spent longer on bringing the evidence forward from the individual reviews into the ROBIS extraction form as recommended by the guidance document, whereas the other two raters only wrote cursory notes.

It is important to highlight that it is advised in the ROBIS guidance document that it is a tool aimed at experienced systematic reviewers and methodologists. We would agree with this recommendation but recognise that this is not often the case in many groups undertaking reviews.

\section{Discussion}

\section{Summary of findings}

The median inter-rater reliability (IRR) agreement for both AMSTAR-2 and ROBIS questions was substantial: $50 \%$ of AMSTAR-2 questions and $46 \%$ of ROBIS questions had substantial agreement or higher. For AMSTAR-2, 460 comparisons were included in the analysis. The median agreement for all questions was 0.61 . For ROBIS, there were 734 comparisons considered for the 24 questions. The median agreement for all

Table 7 Results of AMSTAR-2 for CAM for fibromyalgia reviews

\begin{tabular}{lllll}
\hline Question & No. of studies & $\begin{array}{l}\text { Gwet's AC1/ } \\
\text { Gwet's AC2 }\end{array}$ & 95\% Cl & $p$-value \\
\hline 1 & 15 & 0.66 & $0.32,1.00$ & 0.001 \\
2 & 15 & 1.00 & & \\
3 & 15 & 0.39 & $-0.08,0.86$ & 0.096 \\
4 & 15 & 0.74 & $0.55,0.93$ & $<0.001$ \\
5 & 15 & 0.69 & $0.33,1.00$ & 0.001 \\
6 & 15 & 0.65 & $0.26,1.00$ & 0.003 \\
7 & 15 & 1.00 & & \\
8 & 15 & 0.20 & $0.02,0.38$ & 0.031 \\
9 & 15 & 0.37 & $0.16,0.59$ & 0.002 \\
10 & 15 & 1.00 & $0.85,1.00$ & $<0.001$ \\
11 & 7 & 0.66 & $0.01,1.00$ & 0.047 \\
12 & 7 & 0.52 & $-0.11,1.00$ & 0.091 \\
13 & 15 & 0.62 & $0.26,0.98$ & 0.002 \\
14 & 15 & 0.20 & $-0.17,0.57$ & 0.270 \\
15 & 7 & 0.70 & $0.10,1.00$ & 0.029 \\
16 & 15 & 0.55 & $0.14,0.96$ & 0.013 \\
\hline
\end{tabular}

Twenty missing ratings. Italicised areas are considered the critical questions 
Table 8 Inter-rater agreement

\begin{tabular}{|c|c|c|c|c|}
\hline ROBIS question & No. of studies & $\begin{array}{l}\text { Gwet's AC1/ } \\
\text { Gwet's AC2 }\end{array}$ & $95 \% \mathrm{Cl}$ & $p$-value \\
\hline \multicolumn{5}{|l|}{ Domain 1: study eligibility criteria } \\
\hline 1.1 & 14 & 0.73 & $0.46,1.00$ & $<0.001$ \\
\hline 1.2 & 15 & 0.70 & $0.45,0.95$ & $<0.001$ \\
\hline 1.3 & 15 & 0.62 & $0.39,0.84$ & $<0.001$ \\
\hline 1.4 & 15 & 0.54 & $0.32,0.76$ & $<0.001$ \\
\hline 1.5 & 15 & 0.64 & $0.40,0.88$ & $<0.001$ \\
\hline Domain 1 Concerns regarding specification of study eligibility criteria & 15 & 0.61 & $0.29,0.92$ & 0.001 \\
\hline \multicolumn{5}{|l|}{ Domain 2: identification and selection of studies } \\
\hline 2.1 & 15 & 0.53 & $0.36,0.69$ & $<0.001$ \\
\hline 2.2 & 14 & 0.42 & $0.16,0.69$ & 0.005 \\
\hline 2.3 & 15 & 0.72 & $0.53,0.92$ & $<0.001$ \\
\hline 2.4 & 15 & 0.31 & $-0.08,0.70$ & 0.110 \\
\hline 2.5 & 15 & 0.56 & $0.14,0.99$ & 0.013 \\
\hline Domain 2Concerns regarding methods used to identify and/or select studies & 15 & 0.29 & $0.03,0.55$ & 0.031 \\
\hline \multicolumn{5}{|l|}{ Domain 3: data collection and study appraisal } \\
\hline 3.1 & 15 & 0.95 & $0.66,1.00$ & $<0.001$ \\
\hline 3.2 & 15 & 0.65 & $0.47,0.84$ & $<0.001$ \\
\hline 3.3 & 15 & 0.57 & $0.40,0.74$ & $<0.001$ \\
\hline 3.4 & 15 & 0.55 & $0.23,0.88$ & 0.003 \\
\hline 3.5 & 15 & 0.81 & $0.51,1.00$ & $<0.001$ \\
\hline Domain 3 Concerns regarding methods used to collect data and appraise studies & 15 & 0.52 & $0.19,0.83$ & 0.004 \\
\hline \multicolumn{5}{|l|}{ Domain 4: synthesis and findings } \\
\hline 4.1 & 15 & 0.55 & $0.33,0.77$ & $<0.001$ \\
\hline 4.2 & 13 & 0.55 & $0.29,0.81$ & 0.001 \\
\hline 4.3 & 15 & 0.80 & $0.62,0.98$ & $<0.001$ \\
\hline 4.4 & 15 & 0.13 & $-0.19,0.45$ & 0.405 \\
\hline 4.5 & 14 & -0.10 & $-0.52,0.33$ & 0.633 \\
\hline 4.6 & 15 & 0.23 & $-0.17,0.64$ & 0.235 \\
\hline Domain 4Concerns regarding the synthesis and findings & 15 & 0.18 & $-0.08,0.44$ & 0.154 \\
\hline \multicolumn{5}{|l|}{ Risk of bias in the review } \\
\hline A & 15 & 0.10 & $-0.25,0.44$ & 0.552 \\
\hline B & 15 & 0.61 & $0.40,0.83$ & $<0.001$ \\
\hline C & 15 & 0.39 & $0.01,0.76$ & 0.009 \\
\hline$R O B$ & 15 & 0.43 & $0.10,0.77$ & 0.015 \\
\hline
\end{tabular}

Six ratings missing

questions was also 0.61 . It is interesting that the median IRR agreement for both tools was 0.61 , demonstrating a similar level of rating between the two scales.

Results were similar when conducting the analysis for fibromyalgia and colic reviews separately (see appendix for independent overview results). For fibromyalgia, the median IRR value was 0.66 for the AMSTAR-2 questions compared to 0.56 for the ROBIS questions. For the colic studies both AMSTAR-2 and ROBIS had a similar median ( 0.60 for AMSTAR-2 and 0.63 for ROBIS).
It must also be considered that the ROBIS questions include more categories than most of the AMSTAR-2 questions. Most AMSTAR-2 questions are binary. Interrater agreement tends to be lower when there are more categories, as there are more possibilities for disagreement. Similarly, ROBIS includes more questions than AMSTAR-2 which can also result in more disagreement. However, despite these differences, the median agreement was the same for the AMSTAR-2 and ROBIS questions. 
Table 9 The risk of bias and study quality for each fibromyalgia review

\begin{tabular}{lll}
\hline Fibromyalgia & AMSTAR-2 & ROBIS \\
\hline $\begin{array}{lll}\text { Multiple CAM therapies } \\
\text { Holdcraft 2003 [14] }\end{array}$ & CL & Low \\
Baronowsky 2009 [15] & CL & High \\
Terhorst 2011, 2012 [16, 17] & CL & High \\
De Silva 2010 [18] & CL & High \\
Homoeopathy & & \\
$\begin{array}{l}\text { Perry 2010 [19] } \\
\text { Boehm 2014 [20] }\end{array}$ & CL & Low \\
Chiropractic treatment & CL & High \\
Ernst 2009 [21] & & \\
Acupuncture & $\mathrm{CL}$ & Unclear \\
Mayhew and Ernst 2007 [22] & & \\
Daya 2007 [23] & $\mathrm{CL}$ & Low \\
Langhorst 2010 [24] & $\mathrm{CL}$ & Low \\
Martin-Sanchez 2009 [25] & $\mathrm{CL}$ & Low \\
Cao 2013 [26] & $\mathrm{CL}$ & High \\
Deare 2013 [13] & $\mathrm{CL}$ & Low \\
Yang 2014 [27] & LOW & Low \\
Herbal medicines & $\mathrm{CL}$ & High \\
de Souza Nascimento 2013 [28] & $\mathrm{CL}$ & Low \\
\hline
\end{tabular}

When AMSTAR-2 is low, this should correspond to ROBIS being of high risk of bias. The italicised reviews show discrepancies between the overall rating of quality/bias

\section{Usability of the tools}

Several issues arose when using the ROBIS tool as it required more consideration to complete, which could become problematic in a large review. All three raters felt AMSTAR-2 was more straightforward and user-friendly than ROBIS. This might be because it does not require expertise in systematic reviewing to complete this tool, just knowledge of trial design.

AMSTAR-2 was considered quicker to work through than ROBIS, yet the median timings demonstrated only a slight increase in timing on AMSTAR-2 than ROBIS in two raters, although one rater did take considerably longer on ROBIS than AMSTAR-2. All raters felt domain 4 of ROBIS was particularly difficult to complete if there

Table 10 To compare the distribution of risk of bias and study quality for the fibromyalgia reviews

\begin{tabular}{lllll}
\hline ROBIS & & & & \\
\hline AMSTAR-2 & & High & Low & Unclear \\
& High & 0 & 0 & 0 \\
& Moderate & 0 & 0 & 0 \\
& Low & 0 & 1 & 0 \\
& Critical & 6 & 7 & 1 \\
\hline
\end{tabular}

Table 11 Inter-rater agreement

\begin{tabular}{lllll}
\hline Question & No. of studies & $\begin{array}{l}\text { Gwet's AC1/ } \\
\text { Gwet's AC2 }\end{array}$ & $\mathbf{9 5 \% ~ C l}$ & $p$-value \\
\hline 1 & 16 & 0.73 & $0.43,1.00$ & $<0.001$ \\
2 & 16 & 0.83 & $0.64,1.00$ & $<0.001$ \\
3 & 16 & 0.68 & $0.40,0.96$ & $<0.001$ \\
4 & 16 & 0.58 & $0.34,0.83$ & $<0.001$ \\
5 & 16 & 0.72 & $0.38,1.00$ & $<0.001$ \\
6 & 16 & 0.56 & $0.18,0.95$ & 0.006 \\
7 & 16 & 0.91 & $0.81,1.00$ & $<0.001$ \\
8 & 16 & 0.61 & $0.35,0.87$ & $<0.001$ \\
9 & 16 & 0.87 & $0.69,1.00$ & $<0.001$ \\
10 & 16 & 0.67 & $0.36,0.97$ & $<0.001$ \\
11 & 12 & 0.49 & $0.02,0.96$ & 0.042 \\
12 & 12 & 0.34 & $-0.12,0.80$ & 0.133 \\
13 & 16 & 0.43 & $0.03,0.84$ & 0.038 \\
14 & 16 & 0.22 & $-0.23,0.66$ & 0.321 \\
15 & 12 & 0.58 & $0.16,0.99$ & 0.011 \\
16 & 16 & 0.15 & $-0.25,0.55$ & 0.444 \\
\hline
\end{tabular}

Fifteen missing ratings. Italicised areas are considered the critical questions

was no meta-analysis. Domain 4 would benefit from further development in order to assess reviews without a meta-analysis, as in some ways it is biassed against these types of reviews.

\section{Relationship to background research}

Previous research [7, 8] compared four raters' assessments across 30 systematic reviews. They calculated the IRR using the Fleiss' $k$ [45]. The IRR for scoring the overall confidence in the SRs with AMSTAR-2 was fair (AMSTAR-2: $\kappa=0.30 ; 95 \%$ [confidence interval] CI, 0.17 to 0.43 ). The overall domain in ROBIS was fair (ROBIS: $\mathrm{K}$ $=0.28$; $95 \% \mathrm{CI}, 0.13$ to 0.42 ). Interestingly, for the overall rating, AMSTAR-2 showed a high concordance with ROBIS and a lower concordance with AMSTAR.

We were unable to directly compare our results against Pieper's work, as the Fleiss' kappa ignores the order of the categories (when there are more than two categories), which is why we used Gwet's as it takes the order into account and allows for "partial agreement". Also, Gwet scores tend to be higher than Fleiss scores in general, which makes comparisons difficult to conduct.

In Pieper et al.s [7] study, ROBIS was always applied after AMSTAR-2, and the mean time for scoring AMSTAR-2 was slightly higher than for ROBIS (18 vs. $16 \mathrm{~min})$, with huge variation between the reviewers, whereas in our study, the overall mean time (calculated for colic reviews only) was slightly higher for ROBIS 
Table 12 Inter-rater agreement

\begin{tabular}{|c|c|c|c|c|}
\hline ROBIS question & No. of studies & $\begin{array}{l}\text { Gwet's AC1/ } \\
\text { Gwet's AC2 }\end{array}$ & $95 \% \mathrm{Cl}$ & $p$-value \\
\hline \multicolumn{5}{|l|}{ Domain 1: study eligibility criteria } \\
\hline 1.1 & 16 & 0.57 & $0.17,0.96$ & 0.008 \\
\hline 1.2 & 16 & 0.71 & $0.55,0.87$ & $<0.001$ \\
\hline 1.3 & 16 & 0.76 & $0.61,0.91$ & $<0.001$ \\
\hline 1.4 & 16 & 0.71 & $0.54,0.87$ & $<0.001$ \\
\hline 1.5 & 16 & 0.49 & $0.20,0.77$ & 0.002 \\
\hline Domain 1 Concerns regarding specification of study eligibility criteria & 16 & 0.30 & $-0.03,0.63$ & 0.072 \\
\hline \multicolumn{5}{|l|}{ Domain 2: identification and selection of studies } \\
\hline 2.1 & 16 & 0.54 & $0.34,0.73$ & $<0.001$ \\
\hline 2.2 & 16 & 0.64 & $0.37,0.92$ & $<0.001$ \\
\hline 2.3 & 16 & 0.57 & $0.34,0.81$ & $<0.001$ \\
\hline 2.4 & 16 & 0.50 & $0.27,0.73$ & $<0.001$ \\
\hline 2.5 & 14 & 0.61 & $0.18,1.00$ & $<0.001$ \\
\hline Domain 2Concerns regarding methods used to identify and/or select studies & 16 & 0.43 & $0.13,0.73$ & 0.008 \\
\hline \multicolumn{5}{|l|}{ Domain 3: data collection and study appraisal } \\
\hline 3.1 & 14 & 0.82 & $0.51,1.00$ & $<0.001$ \\
\hline 3.2 & 16 & 0.70 & $0.44,0.96$ & $<0.001$ \\
\hline 3.3 & 16 & 0.72 & $0.52,0.92$ & $<0.001$ \\
\hline 3.4 & 16 & 0.92 & $0.83,1.00$ & $<0.001$ \\
\hline 3.5 & 15 & 0.66 & $0.21,1.00$ & 0.007 \\
\hline Domain 3 Concerns regarding methods used to collect data and appraise studies & 16 & 0.61 & $0.32,0.89$ & $<0.001$ \\
\hline \multicolumn{5}{|l|}{ Domain 4: synthesis and findings } \\
\hline 4.1 & 16 & 0.65 & $0.45,0.86$ & $<0.001$ \\
\hline 4.2 & 16 & 0.42 & $0.11,0.73$ & 0.011 \\
\hline 4.3 & 16 & 0.73 & $0.58,0.88$ & $<0.001$ \\
\hline 4.4 & 16 & 0.23 & $-0.02,0.48$ & 0.072 \\
\hline 4.5 & 16 & 0.40 & $0.22,0.57$ & $<0.001$ \\
\hline 4.6 & 16 & 0.55 & $0.32,0.77$ & $<0.001$ \\
\hline Domain 4Concerns regarding the synthesis and findings & 16 & 0.17 & $-0.17,0.50$ & 0.305 \\
\hline \multicolumn{5}{|l|}{ Risk of bias in the review } \\
\hline A & 16 & 0.47 & $0.28,0.65$ & 0.015 \\
\hline B & 16 & 0.69 & $0.55,0.82$ & $<0.001$ \\
\hline C & 16 & 0.54 & $0.37,0.72$ & $<0.001$ \\
\hline$R O B$ & 16 & 0.47 & $0.17,0.77$ & 0.004 \\
\hline
\end{tabular}

Three ratings missing

than for AMSTAR-2 (24.4 min compared to $14.3 \mathrm{~min}$ ), although the mean ROBIS result was largely influenced by one rater.

\section{Potential bias in the overview process}

One author evaluated their own work using AMSTAR-2 and ROBIS (RP: [19, 29]), although this work was also independently assessed by two other reviewers (VL, PD). In addition, one of the developers of ROBIS (PD) applied the ROBIS tool to assess the included reviews.
We had not planned to complete an IRR assessment of the two scales whilst completing these two overviews of reviews; therefore, we did not apply strict criteria to our assessment schedule, i.e., we did not apply the tools in any particular order. We also did not complete timings for some of our assessments in a systematic way.

Another issue is we compared our ratings over time, i.e., a batch of five papers were discussed before the next batch was assessed; this is likely to have led to greater consistency between the raters over time, but our numbers were too small to check this. 
Table 13 The risk of bias and study quality for each colic review

\begin{tabular}{|c|c|c|c|}
\hline Colic & \multicolumn{2}{|c|}{ AMSTAR-2 } & ROBIS \\
\hline \multicolumn{4}{|l|}{ Multiple CAM therapies } \\
\hline Perry $2011[29]$ & \multicolumn{2}{|l|}{ Low } & Low \\
\hline Bruyas-Bertholon 2012 [30] & \multicolumn{2}{|l|}{$\mathrm{CL}$} & High \\
\hline Harb 2016 [31] & \multicolumn{2}{|l|}{$\mathrm{CL}$} & High \\
\hline Gutierrez-Castrellon 2017 [32] & \multicolumn{2}{|l|}{$\mathrm{CL}$} & High \\
\hline \multicolumn{4}{|l|}{ Manipulation therapies } \\
\hline Dobson 2012 [33] & \multicolumn{2}{|l|}{ High } & Low \\
\hline Gleberzon 2012 [34] & \multicolumn{2}{|l|}{$\mathrm{CL}$} & High \\
\hline Carnes 2017 [35] & \multicolumn{2}{|l|}{$\mathrm{CL}$} & Unclear \\
\hline \multicolumn{4}{|l|}{ Acupuncture } \\
\hline Skejeie 2018 [36] & \multicolumn{2}{|l|}{ Low } & Unclear \\
\hline \multicolumn{4}{|l|}{ Herbal medicine } \\
\hline Anheyer 2017 [37] & \multicolumn{2}{|l|}{$\mathrm{CL}$} & High \\
\hline \multicolumn{4}{|l|}{ Probiotics } \\
\hline Sung 2013 [38] & \multicolumn{2}{|l|}{$\mathrm{CL}$} & Unclear \\
\hline Anabrees 2013 [39] & \multicolumn{2}{|l|}{ Low } & Low \\
\hline Urbanska 2014 [40] & \multicolumn{2}{|l|}{$\mathrm{CL}$} & High \\
\hline Xu 2015 [41] & $C L$ & & Low \\
\hline Schreck Bird 2017 [42] & $\mathrm{CL}$ & & High \\
\hline Dryl 2018 [43] & $\mathrm{CL}$ & & High \\
\hline Sung 2018 [44] & LOW & & Unclear \\
\hline $\begin{array}{l}\text { When AMSTAR- } 2 \text { is low, this should c } \\
\text { bias. The italicised reviews show disc } \\
\text { quality/bias }\end{array}$ & $\begin{array}{l}\text { spond to ROB } \\
\text { ncies betwee }\end{array}$ & $\begin{array}{l}\text { being } \\
\text { the ove }\end{array}$ & $\begin{array}{l}\text { risk of } \\
\text { ting of }\end{array}$ \\
\hline $\begin{array}{l}\text { Table } 14 \text { To compare the di } \\
\text { quality for the fibromyalgia re }\end{array}$ & $\begin{array}{l}\text { bution of } \\
\text { vS }\end{array}$ & $<$ of & nd study \\
\hline ROBIS & & & \\
\hline AMSTAR-2 & High & Low & Unclear \\
\hline High & 0 & 1 & 0 \\
\hline Moderate & 0 & 0 & 0 \\
\hline Low & 0 & 2 & 1 \\
\hline Critical & 8 & 1 & 3 \\
\hline
\end{tabular}

\section{Conclusion}

In terms of quality assessment, ROBIS is an effective tool for assessing risk of bias in a systematic review but is more difficult to use compared to AMSTAR-2. It is more complex to work through, which might be problematic in a large review. As suggested by the developers of ROBIS; it is best used by experienced systematic reviewers/methodologists. Reviews that included a meta-analysis were easier to rate, however, further developmental work could improve its use in systematic reviews without a meta-analysis. AMSTAR-2 was more user-friendly and was effective at measuring quality of a review but was a less sophisticated tool. Both tools could do with minor changes to help improve their useability for people conducting systematic reviews.

\section{Appendix}

Results of AMSTAR-2 for CAM for fibromyalgia reviews

The inter-rater agreement between the three raters is shown in Table 7.

\section{Results of ROBIS: CAM for fibromyalgia}

The summary of results of ROBIS for fibromyalgia can be seen in Table 8 .

\section{Inter-rater agreement for fibromyalgia}

For AMSTAR-2, 10 out of 16 (62.5\%) questions had substantial agreement or higher between reviewers. There was perfect agreement for questions 2 (did the report of the review contain an explicit statement that the review methods were established prior to the conduct of the review and did the report justify any significant deviations from the protocol?), 7 (did the review authors provide a list of excluded studies and justify the exclusions?) and 10 (did the review authors report

Table 15 Criteria for assessing confidence in AMSTAR-2 (Shea et al. [20])

\section{Rating overall confidence in the results of the review}

1. High

(a) No or one non-critical weakness. The systematic review provides an accurate and comprehensive summary of the results of the available studies that address the question of interest

2. Moderate

(a) More than one non-critical weakness*. The systematic review has more than one weakness but no critical flaws. It may provide an accurate summary of the results of the available studies that were included in the review

3. Low

(a) One critical flaw with or without non-critical weaknesses. The review has a critical flaw and may not provide an accurate and comprehensive summary of the available studies that address the question of interest

4. Critically low

(a) More than one critical flaw with or without non-critical weaknesses. The review has more than one critical flaw and should not be relied on to provide an accurate and comprehensive summary of the available studies

*Multiple non-critical weaknesses may diminish confidence in the review and it may be appropriate to move the overall appraisal down from moderate to low confidence 
on the sources of funding for the studies included in the review?). The median agreement for all questions was 0.65 . Ratings from a reviewer were missing in 20 instances overall.

Ten out of 24 (41.7\%) questions for ROBIS had at least substantial agreement. Questions 3.1 (were efforts made to minimise error in data collection?) and 3.5 (were efforts made to minimise error in risk of bias assessment?) had almost perfect agreement. The median agreement for all questions was 0.55 . The agreement was different for each ROBIS domain with substantial being the highest agreement (for missing in 6 instances). The raters gave a rating of "no information" in 93 cases. In most of these cases (65), the other two raters gave a different rating. There were 5 instances where all reviewers reported "no information". The most common questions for "no information" were questions 1.1 (did the review adhere to predefined objectives and eligibility criteria? 13 times), 4.2 (were all pre-defined analyses reported or departures explained? 13 times) and 4.5 (were the findings robust, e.g. as demonstrated through funnel plot or sensitivity analyses? 11 times) .

Tables 9 and 10

\section{Results of AMSTAR-2: CAM for colic}

The inter-rater agreement between the three raters is shown in Table 11.

\section{Results of ROBIS: CAM for colic}

The inter-rater agreement between the three raters is shown in Table 12

\section{Inter-rater agreement for colic}

Eight of 16 (50\%) AMSTAR-2 questions had substantial agreement or higher. There was almost perfect agreement for questions 2 (did the report of the review contain an explicit statement that the review methods were established prior to the conduct of the review and did the report justify any significant deviations from the protocol?), 7 (did the review authors provide a list of excluded studies and justify the exclusions?) and 9 (did the review authors use a satisfactory technique for assessing the risk of bias (RoB) in individual studies that were included in the review?). The median score for all questions was 0.60 . Ratings from a reviewer were missing in 15 instances overall.

Thirteen of 24 (54.2\%) ROBIS questions had substantial agreement or higher. There was almost perfect agreement for questions 3.1 (were efforts made to minimise error in data collection?) and 3.4 (was risk of bias (or methodological quality) formally assessed using appropriate criteria?). The median score for all questions was 0.63 . The agreement was different for each ROBIS domain with substantial being the highest agreement (for domain 3). The agreement for the risk of bias was moderate. Ratings from a reviewer were missing in 3 instances. There were 66 ratings of "no information". There were 3 instances where the reviewers were in agreement. In 42 cases, only one reviewer said "no information". The most common questions were questions 1.1 (did the review adhere to predefined objectives and eligibility criteria? 10 times), 3.5 (were efforts made to minimise error in risk of bias assessment? 8 times) and 4.2 (were all pre-defined analyses reported or departures explained? 9 times).

Tables 13, 14 and 15

\section{Abbreviations}

CAM: Complementary and alternative medicine; AMSTAR: Assessment of Multiple Systematic Reviews; PICO: Population, intervention, control group, outcome; ROBIS: Risk of Bias in Systematic reviews; IRR: Inter-rater reliability.

\section{Acknowledgements}

We thank Professor Rachel Churchill for the initial idea to compare the two assessment tools and Dr Chris Penfold for checking domain 4 in the ROBIS tool.

\section{Authors' contributions}

RP assessed all papers using AMSTAR-2 and ROBIS and contributed to the paper. PD assessed all papers using AMSTAR-2 and ROBIS and contributed to the paper. VL assessed all papers using AMSTAR-2 and ROBIS and contributed to the paper. AW conducted the inter-rater reliability analyses and contributed to the paper. The authors read and approved the final manuscript.

\section{Funding}

The work of RP and AW was funded by National Institutes of Health Research (NIHR) Biomedical Research Centre at the University Hospitals Bristol and Weston NHS Foundation Trust. Philippa Davies'time was supported by the National Institute for Health Research Applied Research Collaboration West (NIHR ARC West) at University Hospitals Bristol NHS Foundation Trust. The views expressed are those of the authors and not necessarily those of the $\mathrm{NHS}$, the NIHR or the Department of Health.

Availability of data and materials

Not relevant.

\section{Declarations}

Ethics approval and consent to participate

Not relevant.

\section{Competing interests}

Rachel Perry was an author on two of the papers under review. Philippa Davies was involved in the development of ROBIS. The other authors declare that they have no competing interests.

\section{Author details}

${ }^{1}$ National Institute for Health Research Bristol Biomedical Research Centre, University Hospitals Bristol and Weston NHS Foundation Trust and University of Bristol, Bristol, UK. ${ }^{2}$ The National Institute for Health Research Applied Research Collaboration West (NIHR ARC West) at University Hospitals Bristol NHS Foundation Trust, Bristol, UK. ${ }^{3}$ Population Health Sciences, Bristol Medical School, University of Bristol, Bristol, UK. 
Received: 8 March 2021 Accepted: 16 September 2021

Published online: 25 October 2021

\section{References}

1. Murad H, Asi N, Alsawas M. New evidence pyramid. BMJ Evid Based Med. 2016;21:125-7.

2. Shea BJ, Grimshaw JM, Wells GA, Boers M, Andersson N, Hamel C, et al. Development of AMSTAR: a measurement tool to assess the methodological quality of systematic reviews. BMC Med Res Methodol. 2007;15(7):10

3. Shea BJ, Hamel C, Wells GA, Bouter LM, Kristjansson E, Grimshaw J, et al. AMSTAR is a reliable and valid measurement tool to assess the methodological quality of systematic reviews. J Clin Epidemiol. 2009;62:1013-20.

4. Burda BU, Holmer HK, Norris SL. Limitations of A Measurement Tool to Assess Systematic Reviews (AMSTAR) and suggestions for improvement. Syst Rev. 2016;5:58

5. Shea BJ, Reeves BC, Wells G, Thuku M, Hamel C, Moran J, et al. AMSTAR 2: a critical appraisal tool for systematic reviews that include randomised or non-randomised studies of healthcare interventions, or both. BMJ. 2017;358:j4008.

6. Whiting P, Savović J, Higgins JP, Caldwell DM, Reeves BC, Shea B, et al. ROBIS group. ROBIS: a new tool to assess risk of bias in systematic reviews was developed. J Clin Epidemiol. 2016;69:225-34.

7. Pieper D, Puljak L, González-Lorenzo M, Minozzi S. Minor differences were found between AMSTAR 2 and ROBIS in the assessment of systematic reviews including both randomized and nonrandomized studies. J Clin Epidemiol. 2019;108:26-33.

8. Lorenz RC, Matthias K, Pieper D, Wegewitz U, Morche J, Nocon M, et al. A psychometric study found AMSTAR-2 to be a valid and moderately reliable appraisal tool. J Clin Epidemiol. 2019;114:133-40.

9. Perry R, Leach V, Davies P, Penfold C, Ness A, Churchill R. An overview of systematic reviews of complementary and alternative therapies for fibromyalgia using both AMSTAR and ROBIS as quality assessment tools. Syst Rev. 2017;6(1):97.

10. Perry $R$, Leach $V$, Penfold $C$, Davies P. An overview of systematic reviews of complementary and alternative therapies for infantile colic. Syst Rev. 2019;8(1):271.

11. Gwet KL. Handbook of inter-rater reliability: The definitive guide to measuring the extent of agreement among raters. 4th ed. Gaithersburg: Advanced Analytics, LLC; 2014.

12. Landis JR, Koch GG. The measurement of observer agreement for categorical data. Biometrics. 1977;33:159-74.

13. Deare JC, Zheng Z, Xue CC, Liu JP, Shang J, Scott SW, et al. Acupuncture for treating fibromyalgia. Cochrane Database Syst Rev. 2013;5:CD007070.

14. Holdcraft LC, Assefi N, Buchwald D. Complementary and alternative medicine in fibromyalgia and related syndromes. Best Pract Res Clin Rheumatol. 2003;17(4):667-83.

15. Baronowsky J, Klose P, Musial F, Haeuser W, Dobos G, Langhorst J. Qualitative systematic review of randomised controlled trials on complementary and alternative medicine treatments in fibromyalgia. Rhuematol Int. 2009;30:1-21.

16. Terhorst L, Schneider MJ, Kim KH, Goozdich LM, Stilley CS. Complementary and alternative medicine in the treatment of pain in fibromyalgia: a systematic review of randomized controlled trials. J Manipulative Physiol Ther. 2011;34(7):483-96.

17. Terhorst $L$, Schneider M. Complementary and alternative medicine in the treatment of pain in fibromyalgia: a systematic review of randomized controlled trials. Portland: From International Research Congress on Integrative Medicine and Health; 2012. 15-18 May 2012

18. De Silva V, El-Metwally A, Ernst E, Lewith G, Macfarlane GJ. Evidence for the efficacy of complementary and alternative medicines in the management of fibromyalgia: a systematic review. Rheumatology. 2010;49(6):1063-8.

19. Perry R, Terry R, Ernst E. A systematic review of homoeopathy for the treatment of fibromyalgia. Clin Rheumatol. 2010;29(5):457-64.

20. Boehm K, Raak C, Cramer H, Lauche R, Ostermann T. Homeopathy in the treatment of fibromyalgia--a comprehensive literature-review and meta-analysis. Complement Ther Med. 2014;22(4):731-42.
21. Ernst E. Chiropractic treatment for fibromyalgia: a systematic review. Clin Rheumatol. 2009;28(10):1175-8.

22. Mayhew E, Ernst E. Acupuncture for fibromyalgia--a systematic review of randomized clinical trials. Rheumatology (Oxford). 2007;46(5):801-4.

23. Daya S. The efficacy of acupuncture in the treatment of fibromyalgia syndrome. J Acupunct Assoc Chartered Physiother. 2007;(3):35-46.

24. Langhorst J, Häuser W, Bernardy K, Lucius H, Settan M, Winkelmann A, et al. Komplementäre und alternative Verfahren beim Fibromyalgiesyndrom. Systematische Übersicht, Metaanalyse und Leitlinie. Schwerpunkt. Schmerz. 2012;26:311-7.

25. Martin-Sanchez E, Torralba E, Díaz-Domínguez E, Barriga A, Martin JL. Efficacy of acupuncture for the treatment of fibromyalgia: systematic review and meta-analysis of randomized trials. Open Rheumatol J. 2009;16(3):25-9.

26. Cao H, Li X, Han M, Liu J. Acupoint stimulation for fibromyalgia: a systematic review of randomised controlled trials. Evid Based Complement Altern Med. 2013;2013:ID 362831

27. Yang B, Yi G, Hong W, Bo C, Zhankui W, Yangyang L, et al. Efficacy of acupuncture on fibromyalgia syndrome: a meta-analysis. J Tradit Chin Med. 2014:34(4):381-91.

28. de Souza Nascimento S, Desantana JM, Nampo FK, et al. Efficacy and safety of medicinal plants or related natural products for fibromyalgia: a systematic review. Evid Based Complement Altern Med. 2013;2013:10.

29. Perry R, Hunt K, Ernst E. Nutritional supplements and other complementary medicines for infantile colic: a systematic review. Pediatrics. 2011;127:720-33.

30. Bruyas-Bertholo V, Lachaux A, Dubois J-P, Fourneret P, Letrilliart L. Quels traitements pour les coliques du nourrisson. Presse Med. 2012;41:e404-10.

31. Harb T, Matsuyama M, David M, Hill RJ. Infant colic —what works: a systematic review of interventions for breast-fed infants. J Pediatr Gastroenterol Nutr. 2016;62(5):668-86.

32. Gutiérrez-Castrellón P, Indrio F, Bolio-Galvis A, et al. Efficacy of LactobacilIus reuteri DSM 17938 for infantile colic. Systematic review with network meta-analysis. Medicine. 2017;96(51):e9375.

33. Dobson D, Lucassen PLBJ, Miller JJ, Vlieger AM, Prescott P, Lewith G. Manipulative therapies for infantile colic. Cochrane Database Syst Rev. 2012; (Issue 12):CD004796. https://doi.org/10.1002/14651858.CD004796. pub2.

34. Gleberzon BJ, Arts J, Mei A, McManus EL. The use of spinal manipulative therapy for pediatric health conditions: a systematic review of the literature. J Can Chiropr Assoc. 2012;56(2):128-41.

35. Carnes D, Plunkett A, Ellwood J, et al. Manual therapy for unsettled, distressed and excessively crying infants: a systematic review and metaanalyses. BMJ Open. 2018;8:e019040.

36. Skjeie H, Skonnord T, Brekke M, Klovning A, Fetveit A, Landgren $\mathrm{K}$, et al. Acupuncture treatments for infantile colic: a systematic review and individual patient data meta-analysis of blinding test validated randomised controlled trials. Scand J Prim Health Care. 2018;36(1):56-69.

37. Anheyer D, Frawley J, Koch AK, Lauche R, Langhorst J, Dobos G, et al. Herbal medicines for gastrointestinal disorders in children and adolescents: a systematic review. Pediatrics. 2017;139(6):e20170062.

38. Sung V, Collett $S$, de Gooyer T, et al. Probiotics to prevent or treat excessive infant crying. JAMA Pediatr. 2013;167(12):1150-7.

39. Anabrees J, Indrio F, Paes B, AlFaleh K. Probiotics for infantile colic: a systematic review. BMC Pediatr. 2013;13:186.

40. Urbanska M, Szajewska H. The efficacy of Lactobacillus reuteri DSM 17938 in infants and children: a review of the current evidence. Eur J Pediatr. 2014:173:1327-37.

41. Xu M, Wang J, Wang N, Sun F, Wang L, Liu XH. The efficacy and safety of the probiotic bacterium Lactobacillus reuteri DSM 17938 for infantile colic: a meta-analysis of randomized controlled trials. PLoS One. 2015;10(10):e0141445.

42. Schreck Bird A, Gregory PJ, Jalloh MA, Risoldi Cochrane Z, Hein DJ. Probiotics for the treatment of infantile colic: a systematic review. J Pharm Pract. 2017;30(3):366-74.

43. Dryl R, Szajewska H. Probiotics for management of infantile colic: a systematic review of randomized controlled trials. Arch Med Sci. 2018;14(5):1137-43. 
44. Sung V, D'Amico F, Cabana MD, Chau K, Koren G, Savino F, et al. Lactobacillus reuteri to Treat Infant Colic: A Meta-analysis. Pediatrics. 2017;141(1):e20171811.

45. Fleiss JL. Measuring nominal scale agreement among many raters. Psychol Bull. 1971;76(5):378.

\section{Publisher's Note}

Springer Nature remains neutral with regard to jurisdictional claims in published maps and institutional affiliations.
Ready to submit your research? Choose BMC and benefit from:

- fast, convenient online submission

- thorough peer review by experienced researchers in your field

- rapid publication on acceptance

- support for research data, including large and complex data types

- gold Open Access which fosters wider collaboration and increased citations

- maximum visibility for your research: over $100 \mathrm{M}$ website views per year

At BMC, research is always in progress.

Learn more biomedcentral.com/submissions 